\title{
Endodontic Management of a Mandibular First Molar with Four Canals in a Distal Root by Using Cone-Beam Computed Tomography: a Case Report
}

\author{
Hani Baziar ${ }^{1}$, Farzaneh Daneshvar ${ }^{1}$, Abbas Mohammadi², Hamid Jafarzadeh ${ }^{3}$ \\ ${ }^{1}$ Department of Endodontics, Faculty of Dentistry, Zahedan University of Medical Sciences, Zahedan, Iran. \\ ${ }^{2}$ Department of Oral and Maxillofacial Radiology, Faculty of Dentistry, Zahedan University of Medical Sciences, Zahedan, \\ Iran. \\ ${ }^{3}$ Dental Research Center, Department of Endodontics, Faculty of Dentistry, Mashhad University of Medical Sciences, \\ Mashhad, Iran.
}

\author{
Corresponding Author: \\ Hamid Jafarzadeh \\ Faculty of Dentistry and Dental Research Center \\ P.O. Box: 91735-984, Vakilabad Blvd, Mashhad \\ Iran \\ Phone: +98-511-8829501 \\ Fax: +98-511-8829500 \\ E-mail: hamid j365@yahoo.com; JafarzadehBH@mums.ac.ir
}

\begin{abstract}
Background: Aberrations in the root canal anatomy are clinically challenging for clinicians. Mandibular first molars usually have 2 roots and 3 or 4 canals, but various combinations may exist. A distal root with three canals is rare and its incidence in literature is about $0.2-3 \%$. As a diagnostic tool, cone-beam computed tomography (CBCT) may be a better choice for diagnosis of extra roots or canals comparing to conventional radiography.

Methods: An endodontic management of a mandibular first molar with six canals was performed. CBCT was used to confirm the diagnosis and to understand the morphology of the canals.

Results: Evaluation of the axial and coronal slices of CBCT images confirmed the presence of 2 roots and 6 canals. The distal root had four distinct root canal orifices with two apical foramens, being described as type XIV canal configuration.

Conclusions: Dentists should be aware of unexpected canal morphology when performing endodontic treatment. The present case demonstrated the use of CBCT in diagnosis and negotiation of extra canals in a mandibular first molar.
\end{abstract}

Keywords: anatomy; cone-beam computed tomography; molar; tooth root; tooth canal.

Accepted for publication: 17 March 2014

To cite this article:

Baziar H, Daneshvar F, Mohammadi A, Jafarzadeh H. Endodontic Management of a Mandibular First Molar with Four Canals in a Distal Root by Using Cone-Beam Computed Tomography: a Case Report.

URL: http://www.ejomr.org/JOMR/archives/2014/1/e5/v5n1e5ht.pdf

doi: $\underline{10.5037 / j o m r .2014 .5105}$ 


\section{INTRODUCTION}

The main objective of the root canal therapy is thorough debridement of the root canal space followed by complete obturation for creating the three-dimensional seal [1]. According to Nair [2], one of the main reasons associated with unsuccessful treatment is the survival of microorganisms within the root canal system. Vertucci [3] reported a substantial number of failures related to aberrant anatomy, such as missing canals. Therefore, a comprehensive knowledge of the root canal anatomy and its morphological variations is crucial for successful treatment [4].

Over the years, there have been numerous studies describing the internal morphology of teeth, including mandibular first molar [5-10]. The majority of mandibular first molars are two-rooted with two mesial and one or two distal canals. The major variant of the root canal system of mandibular first molar is the presence of a middle mesial canal with $1-15 \%$ incidence [ $[6]$. However, three canals have also been reported in the distal root $[\underline{7}, \underline{8}]$ with an incidence of $0.2-3 \%$ [9]. The management of a mandibular first molar with four distal canals in two separate distal roots was reported by Ghoddusi et al. [10].

Since the introduction of $\mathrm{CBCT}$, this threedimensional technique has been established as important tool for diagnosis and treatment planning in an increasing number of fields in dentistry $[11,12]$. CBCT has the ability of overcoming the limitations of conventional radiography such as three-dimensional evaluation of the complex canal anatomy during endodontic treatment [13]. An important benefit of $\mathrm{CBCT}$ is in diagnosis of extra roots or canals. Tu et al. [14] showed a higher prevalence of extra roots in the mandibular first molars assessed by CBCT in comparison to conventional radiography.

This case report presents the successful, non-surgical endodontic treatment of a mandibular first molar with four canals in a distal root diagnosed by cone-beam computed tomographic evaluation.

\section{CASE DESCRIPTION AND RESULTS}

A 42-year-old male patient was referred to the dental office with chief complaint of severe spontaneous pain in the left mandibular first molar. The patient's medical history was non-contributory.

The clinical examination showed extensive amalgam restoration of this tooth. Vitality tests (cold by ice stick, heat by warm instrument, and electric test by a pulp tester) were negative; however, the tooth was tender to percussion. Periapical radiographic examination revealed a deep restoration near distal pulp horn with no signs of periapical radiolucency and aberrant anatomy (Figure 1A). The clinical diagnosis of necrotic pulp with acute apical periodontitis was made, and root canal therapy was planned.

The patient was anesthetized with $2 \%$ lidocaine with 1:80,000 epinephrine. After rubber dam isolation, endodontic access cavity was made. The pulp chamber was repeatedly flushed with $5 \%$ sodium hypochlorite to remove necrotic tissue and microorganisms. Inspection of the pulp chamber revealed four canal openings in the distal root and two in the mesial root. In the distal root, the third and fourth canals were located between distobuccal and distolingual canals. The working lengths were established with an electronic apex locator (Root ZX, Morita, Tokyo, Japan) and a radiograph was taken (Figure 1B). The presence of six canals was confirmed and pulpectomy was performed.

To confirm this unusual canal anatomy and to understand its configuration, CBCT imaging of the tooth was performed. Calcium hydroxide was placed as temporary dressing and the access cavity was sealed by zinc oxide-eugenol cement. After obtaining the informed consent from the patient, CBCT of the mandible with the focus on the left mandibular first molar was performed (Vatech, PaX-Reve 3D plus, 5.5 $\mathrm{cm}$ field of view, and voxel size of $0.08 \mathrm{~mm}$ ). Axial, coronal, and sagital CBCT slices revealed six canals (four in the distal root and two in the mesial root) in the referred tooth (Figure 1C - E).

At the next visit, the patient was asymptomatic. Root canal preparation was performed with ProTaper rotary instruments (Dentsply Maillefer, Ballaigues, Switzerland) in crown-down technique. Irrigation was performed with $2.5 \%$ sodium hypochlorite during instrumentation, followed by $17 \%$ EDTA. After a final rinse with normal saline, canals were dried with sterile paper points (Ariadent, Tehran, Iran) and obturated with gutta-percha (Ariadent, Tehran, Iran) and $\mathrm{AH}$ Plus sealer (Dentsply, Maillefer, Konstanz, Germany) using cold lateral condensation technique (Figure 1F). Then, the patient was refereed for crown restoration. Six months after the endodontic treatment, the patient was asymptomatic (Figure 1G).

\section{DISCUSSION}

The diagnosis and treatment of extra roots or canals in mandibular first molars is definitely an endodontic challenge. A comprehensive understanding of 


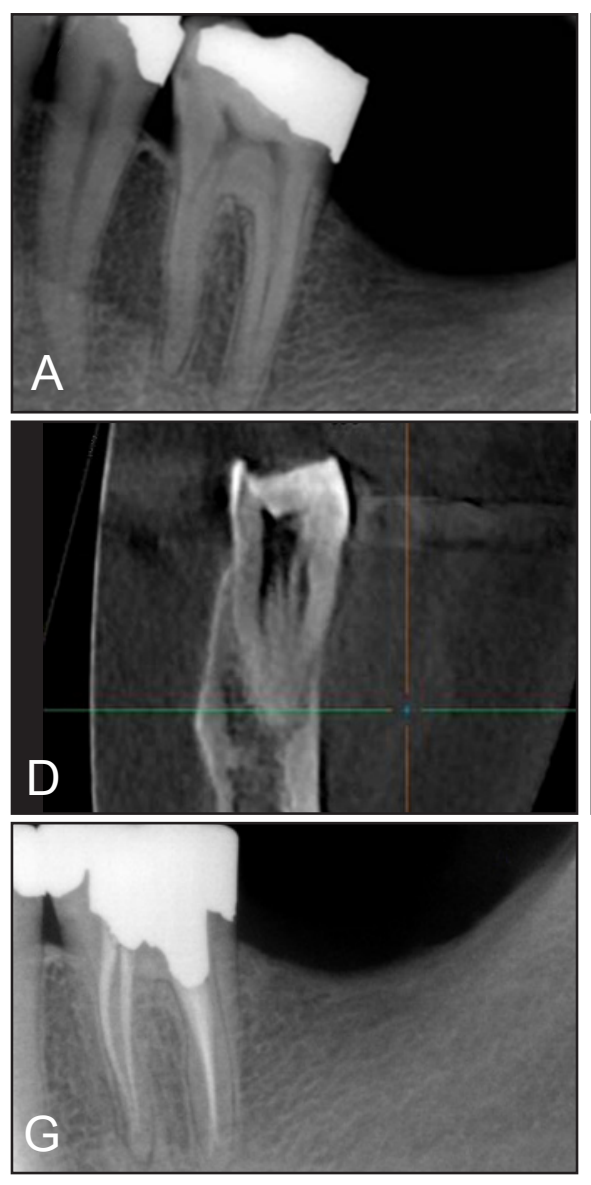

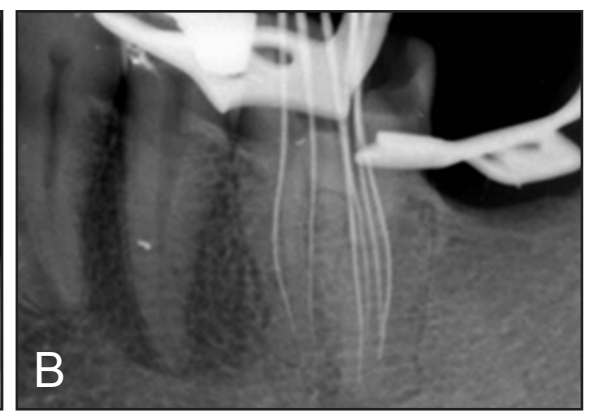
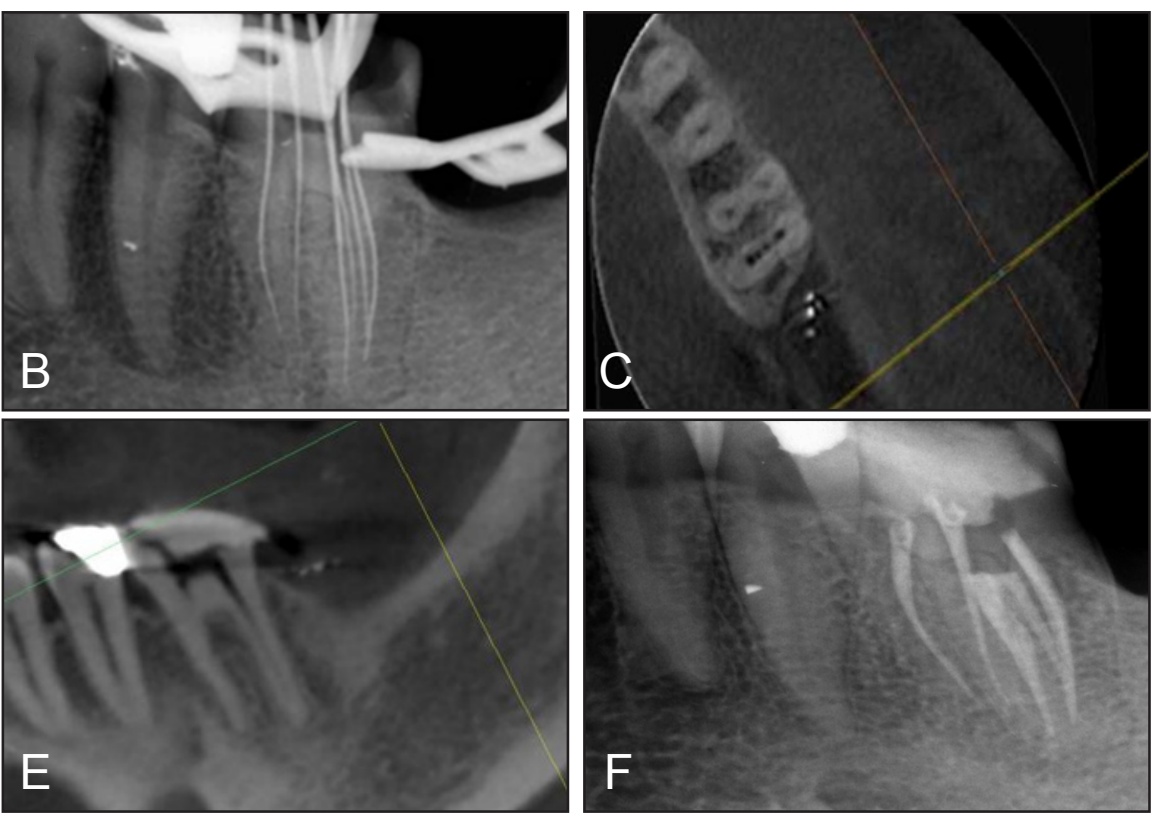

Figure 1.

$\mathrm{A}=$ Preoperative periapical radiograph of a left mandibular first molar.

$\mathrm{B}=$ Periapical radiograph showing the working length determination of six root canals.

$\mathrm{C}=$ Enlarged axial CBCT image section at the mid-root level showing 4 canals in the distal root and 2 canals in the mesial root.

$\mathrm{D}=$ Enlarged coronal section of the distal root showing the configuration of the four canals. $\mathrm{E}=$ Enlarged sagital section of the distal root showing the overlapping of the four canals.

$\mathrm{F}=$ Postoperative periapical radiograph showing all root canals.

$\mathrm{G}=$ Six months follow-up of the root canal treatment. the most common root canal configuration and its variations is essential to achieve long-term success of the endodontic treatment. Hoen and Pink [15] reported $42 \%$ incidence of missed root or canals in the teeth that needed retreatment. Thus, complete debridement and obturation of the root canal system is an utmost important procedure in endodontics.

Diagnostic imaging is an important tool for locating canal orifices including a careful examination of the pulp chamber floor with a sharp explorer, staining with $1 \%$ methylene blue dye, sodium hypochlorite testing (Champagne bubble test), and visualizing canal bleeding points. Magnifier loupes and operating microscope would also increase the location of hidden canals $[\underline{16}]$.

Anatomical variations in the anatomy of the distal root of mandibular molars may be identified through careful evaluation of multiple angled pretreatment radiographs. Periapical radiographs produce only a two-dimensional image. Thus, they are decreased in value in cases of aberrant anatomy [17]. However, it should be noted that significant constraint in conventional periapical radiography is that it produces a two-dimensional image of a three-dimensional object. So, periapical radiographs are of limited value in cases with complex anatomy [18]. Recently, CBCT has been used in endodontics for the evaluation of the root canal anatomy. An advantage of the computed tomography (CT) scanning over the conventional radiograph is that it permits the operator to look at multiple sections of the roots and their canals [19]. Nance et al. [20] reported that the detection of canals increased significantly by CT scan compared with conventional radiography.

In this case report, CBCT imaging was used for a better understanding of the complex root canal anatomy. Evaluation of the axial and coronal slices of CBCT images confirmed the presence of 2 roots and 6 canals. The distal root had four distinct root canal orifices with two apical foramens, which could be described as type XIV canal configuration, according to Sert and Bayirli [21].

Treatment of extra canals may be challenging to each endodontist or general practitioner; however, the inability to find and properly treat the canals may cause failure. With advance diagnostic aids such as $\mathrm{CBCT}$, these challenges may be overcome.

\section{CONCLUSIONS}

Dentists should be aware of unexpected canal morphology when performing endodontic treatment. The present report demonstrated the use of a cone- 
beam computed tomography examination as a tool for the diagnosis and negotiation of extra canals in the distal root of a mandibular first molar.

\begin{abstract}
ACKNOWLEDGE STATEMENT

AND

DISCLOSURE

The authors wish to thank the members of the Department of Oral and Maxillofacial Radiology and Department of Endodontics (Faculty of Dentistry, Zahedan University of Medical Sciences) for their assistance. The authors report no conflicts of interest related to this report.
\end{abstract}

\section{REFERENCES}

1. Vertucci FJ. Root canal morphology and its relationship to endodontic procedures. Endod Topics 2005;10:3-29. [doi: $10.1111 / \mathrm{j} .1601-1546.2005 .00129 . x$ ]

2. Nair PN. On the causes of persistent apical periodontitis: a review. Int Endod J. 2006 Apr;39(4):249-81. Review. [Medline: 16584489] [doi: 10.1111/j.1365-2591.2006.01099.x]

3. Vertucci FJ. Root canal anatomy of the human permanent teeth. Oral Surg Oral Med Oral Pathol. 1984 Nov;58(5):589-99. [Medline: 6595621]

4. Krasner P, Rankow HJ. Anatomy of the pulp-chamber floor. J Endod. 2004 Jan;30(1):5-16. [Medline: 14760900] [doi: 10.1097/00004770-200401000-00002]

5. Sperber GH, Moreau JL. Study of the number of roots and canals in Senegalese first permanent mandibular molars. Int Endod J. 1998 Mar;31(2):117-22. [Medline: 9868938] [doi: 10.1046/j.1365-2591.1998.00126.x]

6. Baugh D, Wallace J. Middle mesial canal of the mandibular first molar: a case report and literature review. J Endod. 2004 Mar;30(3):185-6. Review. [Medline: 15055441] [doi: 10.1097/00004770-200403000-00015]

7. Stroner WF, Remeikis NA, Carr GB. Mandibular first molar with three distal canals. Oral Surg Oral Med Oral Pathol. 1984 May;57(5):554-7. [Medline: 6587303]

8. Beatty RG, Interian CM. A mandibular first molar with five canals: report of case. J Am Dent Assoc. 1985 Nov;111(5):76971. [Medline: 3864840$]$

9. Kottoor J, Sudha R, Velmurugan N. Middle distal canal of the mandibular first molar: a case report and literature review. Int Endod J. 2010 Aug;43(8):714-22. Epub 2010 May 19. Review. [Medline: 20491988] [doi: $10.1111 / \mathrm{j} .1365-2591.2010 .01737 . \mathrm{x}]$

10. Ghoddusi J, Naghavi N, Zarei M, Rohani E. Mandibular first molar with four distal canals. J Endod. 2007 Dec;33(12):14813. Epub 2007 Oct 22. [Medline: 18037064] [doi: 10.1016/i.joen.2007.08.018]

11. Jeger FB, Lussi A, Bornstein MM, Jacobs R, Janner SF. [Cone beam computed tomography in endodontics: a review for daily clinical practice]. Schweiz Monatsschr Zahnmed. 2013;123(7-8):661-8. Review. German. [Medline: 23966013]

12. Hassan BA. Reliability of periapical radiographs and orthopantomograms in detection of tooth root protrusion in the maxillary sinus: correlation results with cone beam computed tomography. J Oral Maxillofac Res. 2010 Apr 1;1(1):e6. [Medline: 24421962] [doi: 10.5037/jomr.2010.1106] [PMC free article: $\underline{3886038}$ ]

13. Durack C, Patel S. Cone beam computed tomography in endodontics. Braz Dent J. 2012;23(3):179-91. Review. [Medline: 22814684] [doi: 10.1590/S0103-64402012000300001]

14. Tu MG, Liu JF, Dai PW, Chen SY, Hsu JT, Huang HL. Prevalence of three-rooted primary mandibular first molars in Taiwan. J Formos Med Assoc. 2010 Jan;109(1):69-74. [Medline: 20123588] [doi: 10.1016/S0929-6646(10)60023-X]

15. Hoen MM, Pink FE. Contemporary endodontic retreatments: an analysis based on clinical treatment findings. J Endod. 2002 Dec;28(12):834-6. [Medline: 12489654] [doi: 10.1097/00004770-200212000-00010]

16. Jain S. Mandibular first molar with three distal canals. J Conserv Dent. 2011 Oct;14(4):438-9 9. [Medline: 22144821] [doi: 10.4103/0972-0707.87223] [PMC free article: 3227299]

17. Holtzman L. Root canal treatment of mandibular second premolar with four root canals: a case report. Int Endod J. 1998 Sep;31(5):364-6. [Medline: 9823141] [doi: 10.1046/j.1365-2591.1998.00166.x]

18. Gupta S, Jaiswal S, Arora R. Endodontic management of permanent mandibular left first molar with six root canals. Contemp Clin Dent. 2012 Apr;3(Suppl 1):S130-3. [Medline: 22629055] [doi: 10.4103/0976-237X.95124] [PMC free article: $\underline{3354780]}$

19. Patel S, Dawood A, Whaites E, Pitt Ford T. New dimensions in endodontic imaging: part 1. Conventional and alternative radiographic systems. Int Endod J. 2009 Jun;42(6):447-62. Review. [Medline: 19298577] [doi: $10.1111 / \mathrm{j} .1365-2591.2008 .01530 . \mathrm{x}]$

20. Nance R, Tyndall D, Levin LG, Trope M. Identification of root canals in molars by tuned-aperture computed tomography. Int Endod J. 2000 Jul;33(4):392-6. [Medline: 11307216] [doi: 10.1046/j.1365-2591.2000.00330.x ] 
21. Sert S, Bayirli GS. Evaluation of the root canal configurations of the mandibular and maxillary permanent teeth by gender in the Turkish population. J Endod. 2004 Jun;30(6):391-8. [Medline: 15167464] [doi: 10.1097/00004770-200406000-00004]

\section{To cite this article:}

Baziar H, Daneshvar F, Mohammadi A, Jafarzadeh H. Endodontic Management of a Mandibular First Molar with Four Canals in a Distal Root by Using Cone-Beam Computed Tomography: a Case Report.

J Oral Maxillofac Res 2014;5(1):e5

URL: http://www.ejomr.org/JOMR/archives/2014/1/e5/v5n1e5ht.pdf

doi: $\underline{10.5037 / j o m r .2014 .5105}$

Copyright (C) Baziar H, Daneshvar F, Mohammadi A, Jafarzadeh H. Published in the JOURNAL OF ORAL \& MAXILLOFACIAL RESEARCH (http://www.ejomr.org), 1 April 2014.

This is an open-access article, first published in the JOURNAL OF ORAL \& MAXILLOFACIAL RESEARCH, distributed under the terms of the Creative Commons Attribution-Noncommercial-No Derivative Works 3.0 Unported License, which permits unrestricted non-commercial use, distribution, and reproduction in any medium, provided the original work and is properly cited. The copyright, license information and link to the original publication on (http://www.ejomr.org) must be included. 